УДК 340

12.00.00 Юридические науки

ОРГАНИЗАЦИОННО-ТАКТИЧЕСКИЕ
АСПЕКТЫ ВЗАИМОДЕЙСТВИЯ
УЧАСТНИКОВ-ЧЛЕНОВ СЛЕДСТВЕННО-
ОПЕРАТИВОЙ ГРУППЫ В РАСКРЫТИИ И
РАССЛЕДОВАНИИ МНОГОЭПИЗОДНЫХ
СЛОЖНЫХ ГРУППОВЫХ ПРЕСТУПЛЕНИЙ

Бастрыгин Артем Сергеевич

аспирант очного обучения юридического

факультета

Кубанский Государственный Аграрный

Университет, Краснодар, Россия

В результате проведенного анализа научной и специальной литературы, обобщения судебноследственной и оперативной практики и мнений специалистов-участников следственно-

оперативной группы автор пришел к выводу о том, что в деятельности руководителя следственного органа и органа дознания необходимо предусмотреть механизм контроля за исполнением организационных и иных мероприятий, запланированных в системе взаимодействия. Для этого следует использовать аналитический организационно-методический штаб по управлению взаимодействием членов СОГ. Автор также полагает, что на протяжении всей деятельности СОГ необходимо осуществлять взаимодействие между сотрудниками органов предварительного следствия и дознания, а также должностными лицами, осуществляющими ОРД. Представляется, что под формами взаимодействия следует понимать комплекс совместных согласованных уголовно-процессуальных и организационно-управленческих действий следователя, руководителя СОГ и органа дознания, на основе оперативной или оперативнотактической готовности, построенных в сочетании с методами оперативно-розыскной деятельности и процессуальных действий с соблюдением принципов уголовно-процессуального законодательства и ФЗ «Об ОРД» для непосредственного выполнения назначения уголовно-процессуального законодательства и решения задач ОРД

КлючевЫе слова: СЛЕДСТВЕННО-ОПЕРАТИВНАЯ ГРУППА; МНОГОЭПИЗОДНОЕ ДЕЛО; ВЗАИМОДЕЙСТВИЕ; ОПЕРАТИВНОЕ СОПРОВОЖДЕНИЕ; ОРГАНИЗАЦИОННОТАКТИЧЕСКИЕ АСПЕКТЫ; ОПЕРАТИВНЫЙ СОТРУДНИК; РАССЛЕДОВАНИЕ; ОПЕРАТИВНО-РОЗЫСКНАЯ (ПОИСКОВАЯ) ГРУППА; ОПЕРАТИВНО-ПОИСКОВОЕ ДЕЛО; СЛЕДСТВЕННЫЕ СИТУАЦИИ
UDC 340

Legal sciences

\section{ORGANIZATIONAL AND TACTICAL ASPECTS OF INTERACTION WITHIN AN INVESTIGATIVE TEAM IN THE COURSE OF DETECTION AND INVESTIGATION OF MULTI EPISODE COMPLEX COLLECTIVE CRIMES}

Bastrygin Artem Sergeevich

full-time postgraduate of the Law Faculty

Kuban State Agrarian University, Krasnodar, Russia

As a result of the analysis of scientific and special literature, and summarizing the forensic investigative and operational practices and the views of experts from the investigative team, the author came to the conclusion that the activities of the head of an investigative body and inquiry agency should include a mechanism of control over the execution of organizational and other activities planned for the interaction system. Therefore, an analytical and methodical organizational headquarters to manage the interaction within the investigative team should be used. The author also believes that it's necessary to provide the interaction between the staff of the preliminary investigation and inquiry, as well as officials carrying out the operational searching activity during the whole period of the investigative team activities. The forms of interaction should be presented as a set of cooperative and agreed criminal procedure and organizational and administrative actions of the investigator, the head of the investigative team and the inquiry agency, on the basis of operational or operational and tactical availability in conjunction with the methods of operational and investigative activities and proceedings in compliance with the principles of criminal procedure law and the Federal law "On the OSA" for the purpose of direct execution of the criminal procedure legislation and the solution of tasks of the operational searching activities

Keywords: INVESTIGATIVE TEAM; MULTI EPISODE CASE; INTERACTION; OPERATIONAL SUPPORT; ORGANIZATIONAL AND TACTICAL ASPECTS; OPERATIVE AGENT; INVESTIGATION; OPERATIONAL SEARCHING GROUP; OPERATIONAL SEACHING CASE; INVESTIGATION SITUATIONS 
Doi: 10.21515/1990-4665-127-003

\section{Организационно-тактические аспекты взаимодействия участников- членов следственно-оперативной группы в раскрытии и расследовании многоэпизодных сложных групповых преступлений.}

Взаимодействие в следственно-оперативной группе осуществляется в уголовно-процессуальной и не процессуальной форме. Уголовнопроцессуальное взаимодействие в расследовании преступлений осуществляется в соответствии с нормами уголовного-процессуального законодательства Российской Федерации. Непроцессуальная форма взаимодействия осуществляется в соответствии с нормативно-правовыми актами МВД, ФСБ, СК, МО, Генеральной прокуратуры, ФСИН, СВР Российской Федерации и других ведомств.

Автор не соглашается с мнением А.В. Гордина, который считает, что «статус следственно-оперативной группы, деятельность которой регламентирована Инструкцией утвержденной приказом МВД России № 334 от 20.06.116 г. и Временной инструкцией к приказу ИВД России № 215 от 07.03.2002 г. не легитимной при расследовании преступлений, так как о ее существовании не указано в УПК РФ»[1].

С этим утверждением А.В, Гордина согласиться нельзя, т.к. деятельность следственно-оперативной группы регламентируется не только приказами МВД РФ, но и приказами Генеральной прокуратуры, Следственного Комитета, распоряжением Президента и Правительства России, а также Федеральных законах России «О полиции», «Об оперативно-розыскной деятельности».

Процессуальными основаниями для взаимодействия сотрудников различных служб правоохранительных органов является уголовнопроцессуальное законодательство РФ (ч. 4 ст. 21, ст. 38, 41, 144 и 163 УПК РФ), Федеральный закон «О полиции» и «Об оперативно-розыскной деятельности», нормативно-правовые акты, в которых изложены основные критерии и формы организации и функционирования следственнооперативных групп и организация взаимодействия, оптимальные 
организационно-управленческие формы и приемы использования и функционирования деятельности группы.

Судебно-следственной практике известно, что при проведении согласованных следственных действий в сочетании с оперативнорозыскными мероприятиями достигается максимальное получение криминалистически значимой информации по изобличению, пресечению и предотвращению готовящихся или совершенных преступлений или обнаруженных или изъятых орудий преступления. При проведении поисковой операции достигается максимальное взаимодействие, координации и целеустремленности в действиях входящих в ее структуру сил и средств. Именно это особая структура поисковой тактической операции позволяет получить максимальную надежность результатов. Это достигается за счет сосредоточенного получения информации об искомом объекте (при обыске), широкие и углубленные поисковые мероприятия, связанные с обнаружением, исследованием, использованием различных по своей природе доказательств, другие способы, методы и приемы, направленные на решение одной задачи, достижение локальной или даже сквозной цели высокой эффективности, позволяют получить максимальную надежность результатов.

Мобилизационный ресурс следственно-оперативной группы и умелая организационно-управленческая деятельность позволяет в нужное время и в нужном месте сконцентрировать и интенсивно с оптимальным маневрированием и использованием сил и средств решить наиболее сложные следственные действия и оперативно-розыскные мероприятия и иные криминалистические действия позволяющие решить сквозные и локальные операции, непрерывные, но реализуемые последовательно или параллельно, как отдельная или комплексная поисково-тактическая операция по многоэпизодному уголовному делу.

Достижению отдельных результатов способствует следующие криминалистические принципы: собирание служебной тайны и конспирации, обеспечение безопасности участников операции и граждан, оптимальная затрата сил, средств и времени, динамичность и сочетание единоличия с коллегиальностью при принятии организационно- 
управленческих и уголовно-правовых или процессуальных решений, а также строжайшее соблюдение законности при подготовке и проведении поисковой тактической операции, а также фиксации результатов с целью получения криминалистически значимой информации для формирования доказательств.

Взаимодействие следователя, дознавателя с органом дознания или с оперативно-розыскными подразделениями, специалистом в ходе предварительной проверки сообщения о преступлении, осуществляется в соответствии со ст. 144 УПК РФ и выражается в следующем: 1) при рассмотрении органами предварительного следствия и дознания заявлений и сообщений, проверке наличия оснований к возбуждению уголовного; 2) направлении материалов проверки по данным, полученным в ходе проведения оперативно-розыскных мероприятий, следовательно до решения вопроса о возбуждении уголовного дела; 3) выполнением органом дознания поручений следователя о проверке данных, имеющих значение для установления оснований для возбуждения уголовного дела; 4) о получении образцов для сравнительного исследования с участием специалиста; 5) взаимодействие с экспертом путем назначения судебной экспертизы и участие в ее производстве; 6) участие специалистов в ходе производства осмотра места происшествия, жилища, местности, иного помещения, документов, предметов, трупов; 7) исполнение органом дознания и оперативно-розыскными подразделениями письменные поручения для осуществления оперативно-розыскных и мероприятий.

Наиболее тесное взаимодействие следователя и органа дознания, или должностного лица, осуществляющего оперативно-розыскную деятельность, возникают в начале расследования, когда не выявлено лицо, совершившее преступление; когда преступление неочевидное, с тяжкими и особо тяжкими последствиями; многоэпизодное; лицо, совершившее известно, но скрылось от органа предварительного следствия и дознания и при его розыске; при подготовке обысков, арестов, задержании, особенно при одновременной проверке этих следственных действий в разных, отделенных друг от друга мест. 
Одной из форм взаимодействия подразделений ОВД является в составе СОГ следующих видов: 1) дежурная; 2) целевые и специализированные группы; 3) постоянно действующие межведомственные группы по раскрытию преступлений прошлых лет; 4) межгосударственные группы; совместные группы (бригады) для раскрытия преступления, совершенного ОПГ, сообществом, преступной организацией. В состав бригады, спецотделов создают микро группы: штаб по управлению расследованием преступлений; аналитическая группа, группа по проведению отдельных следственных действий (обыск, задержание и т.д.); оперативно-розыскные и поисковые группы; группы специалистов и экспертов подразделения ЭКП ГУ МВД РФ. Следовательно, в рамках деятельности СОГ с участием подразделений различных ведомств, особенно межгосударственных ведомств важную роль играет следующие основные направления взаимодействия: 1) согласованное планирование следственных и иных процессуальных действий и ОРМ находящихся в производстве СОГ; 2) совместное обсуждение собранной по делу информации и наиболее или наименее плодотворных следственных действий и ОРМ с последующим выявлением допущенных ошибок; 3) ознакомление следствия с результатами ОРД имеющими значение по делу; 4) взаимная информация и планирование следственных действий с учетом имеющихся данных (сведений) и криминалистически значимой информации; 5) выполнение оперработниками отдельных или комплекс поручений следователя; 6) участие оперработников в производстве следственных действий; 7) участие сотрудников Интерпола в решении следующих задач: экстрадиция, т.е. решение вопроса о выдаче лица для уголовного преследования (гл. 54 УПК РФ); подача и исполнение запроса о правовой помощи в виде производства (гл. 53 УПК РФ); подача и исполнение запроса одного правоохранительного учреждения другому о предоставлении такой оперативной помощи, как контролируемая поставка, наблюдение, оперативная съемка, задержание.

Взаимодействие правоохранительных органов автор понимает, как взаимодействие органов предварительного следствия и органа дознания 
подчиненные одному ведомству или министерству, далее это взаимодействие следователя с оперативными сотрудниками уголовного розыска, по борьбе с экономическими преступлениями, при осуществлении оперативно-технических мероприятий с сотрудниками бюро оперативно-технических подразделений, с экспертнокриминалистическими и экспертами учреждений одного ведомства или между правоохранительными органами районного и городского звена, региона или различных регионов РФ и различных государств, как ближнего, так и дальнего зарубежья. В зависимости от степени и характера складывающихся типичных следственных ситуаций, правильной их оценки и выбора комплекса организационно-управленческих, тактических приемов и операций зависит успех (объективности, полноты и достоверности) и достижении положительных результатов, полученных в ходе производства неотложных и первоначальных процессуальных и организационно-управленческих действий.

Автор соглашается с мнением В.М. Усынина, который справедливо считает, что «следственно-оперативные группы представляют собой организационную форму взаимодействия, в связи с чем, их деятельность не должна регламентироваться нормами уголовно-процессуального законодательства. Важнейшей формой взаимодействия является следственная группа, которая состоит из нескольких следователей. Высказано мнение, что оперативные сотрудники не должны входить в состав следственной группы, так как оперативное сопровождение не является процессуальной деятельностью. Включение их в состав указанной группы может быть обусловлено только тем, что обеспечивать оперативное сопровождение должны конкретные оперативные сотрудники, а не различные. Оперативные сотрудники не должны выполнять следственных действий вместо следователей» [2].

Изложенное, с учетом ранее высказанных мнений в научной и специальной юридической литературе, автор считает, что следственнооперативные группы должны состоять из двух групп: следственной группы и оперативно-розыскной (поисковой) группы объявленной совместным приказом руководителя следственного органа и органа дознания. В 
условиях деятельности подразделений СК России, руководитель следственного органа своим постановлением в соответствии с п.1 ч. 1 ст. 39 и ч. 1 и 2 ст. 163 УПК РФ создаётся следственная группа и при необходимости в соответствии с этим постановлением может быть подписан совместный приказ руководителя следственного органа и начальника органа дознания соответствующего уровня о создании следственно-оперативной группы. Действительно, оперативные работники, входящие в состав СОГ не могут выполнять следственные действия самостоятельно, но они вправе по согласованию со следователем участвовать в следственных и иных процессуальных действиях проводимых следователем, членом СОГ.

Изложенное также подтверждается тем, что взаимодействие членов следственной группы и членов оперативно-розыскной (поисковой) группы входящих и объединённые в форме деятельности, как следственнооперативная группа следует рассматривать, как процессуальную и организационную форму взаимодействия. Как ранее автор отмечал следственная группа, выполняет те действия, которые ей поручены руководителем следственно-оперативной группы в соответствии с уголовнопроцессуальным законом, а оперативно-розыскная группа входящая в состав СОГ осуществляет оперативное сопровождение процесса расследования в целом по делу или отдельных следственных действий по поручению руководителя СОГ или следователя расследующего отдельный эпизод по многоэпизодному уголовному делу. В рамках осуществления процессуального взаимодействия любой следователь следственнооперативной группы может направить отдельное поручение органу дознания в рамках тех вопросов, которые он рассматривает при производстве отдельных эпизодов преступной деятельности. Отдельное поручение направляется на имя начальника органа дознания с указанием конкретных сотрудников, которым нужно поручить производство данного отдельного поручения. Включение оперативных сотрудников в состав следственнооперативной группы не предполагает выполнение ими любых следственных действий по поручению следователя, а должно быть связано с обеспечением оперативного сопровождения отдельного эпизода расследуемого 
многоэпизодного дела.

Анализ судебно-следственной и оперативной практики позволяет высказать мнение, что оперативно-розыскное сопровождение многоэпизодное, сложное по объему, неочевидное, тяжкое и особо тяжкое преступление, как правило, обеспечивает оперативно-розыскная (поисковая) группа совместно со следственной группой объединённой приказом начальника ОВД в единую группу, как следственно-оперативная группа для осуществления процессуальной и организационно-управленческой деятельности по делу с момента поступления в орган предварительного следствия и дознания сообщения о преступлении. Результаты оперативного сопровождения могут направляться руководителю СОГ согласно Инструкции «О порядке предоставления следователю, дознавателю и в суд материалов оперативно-розыскной деятельности». При таком взаимодействии группы следователей с группой должностных лиц, осуществляющих оперативно-розыскную деятельность полученные результаты могут использоваться для принятия процессуальных решений, организационных и управленческих решений с учетом сложившихся следственных ситуаций, выдвижения и проверки следственных версий, а также их планирования для определения тактики проведения следственных действий.

Следовательно, наиболее эффективно используемой формой взаимодействия следователя и оперативного сотрудника, членов следственно-оперативной группы на всех этапах предварительного следствия являются: 1) о производстве оперативно-розыскных (поисковых мероприятий); 2) совместная деятельность по реализации материалов оперативно-розыскной деятельности в ходе рассмотрения сообщения о преступлении, а также на первоначальном и последующем этапе расследования преступлений; 3) при применение мер процессуального принуждения; 4) при избрании меры пресечения, при обеспечении оперативного сопровождения деятельности следователя и обеспечения защиты участников уголовного судопроизводства.

Главные условия в деятельности следователя и органа дознания, либо с должностным лицом, осуществляющим оперативно-розыскную 
деятельность, или с конкретным сотрудником оперативно-розыскного подразделения, которому предоставлено право осуществлять оперативнорозыскную деятельность согласно Приказа МВД России являются следующее: совместное согласованное стратегическое планирование, либо согласование отдельных планов, имеющихся у следователя и оперработника, с целью обеспечения координации действий и четкого разграничения обязанностей в процессе совместной работы; взаимный и своевременный обмен информацией в процессе разработки версий и их проверки; совместный анализ складывающейся следственной ситуации и собранных по делу данных, полученных в процессе производства указанных действий и мероприятий, а при необходимости последующая корректировка плана (планов); обсуждение решений о производстве следственных и иных процессуальных действий и возможных тактических приемов, использование которых наиболее целесообразно.

Автор и опрошенные респонденты (следователи - 92\%) полагают, что результаты ОРД в соответствии со ст.ст. 87-89 УПК РФ и сформировавшиеся согласно внутреннего убеждения субъекта расследования на основе собирания, проверки и оценки доказательств, должны допускаться в процессе доказывания. Главная цель следственнооперативной группы, это четкое планомерное взаимодействие всех членов для выявления, раскрытия и расследования неочевидных, многоэпизодных, сложных и (или) имеющих общественный резонанс, объёмных дел. Таким образом, в уголовно-процессуальном законе, в частности, ч. 1 ст. 163 УПК РФ требует, и как полагает О.О. Докучаев «к работе СГ могут быть привлечены должностные лица органов, осуществляющих оперативнорозыскную деятельность (ОРД)» [3]. К сожалению ст. 163 УПК РФ четко не регламентирует условия и порядок привлечения к участию в деятельности СГ должностных лиц, осуществляющих ОРД, а также не понятно кто из должностных лиц имеет право привлекать должностных лиц, осуществляющих ОРД в деятельность СГ, т.е. руководителем следственного органа или руководителя следственной группы. Поэтому, как правило, следователь член СГ или СОГ которому поручено расследовать отдельный 
эпизод многоэпизодного дела, выделенное в отдельное производство руководствуется своими полномочиями предусмотренными в п. 4 ч. 2 ст. 38 УПК РФ. В других положениях норм УПК РФ не предусмотрены положения для реального взаимодействия или совместной деятельности в выявлении, раскрытии и расследовании преступлений СГ, либо СОГ. В связи с этим, А.А. Эскархопуло и И.И. Беляев СОГ не включили в число правовых форм взаимодействия[4]. М.С, Кузнецов пишет о создании постоянно действующего и временного СОГ как о форме организации субъективного состава участников взаимодействия[5].

Изложенное позволяет высказать мнение о том, что для более квалифицированного выполнения возложенных на введенного оперработника в состав, должен быть выведен приказом начальника органа дознания из непосредственного подчинения своего начальника на время участия СОГа и выполнять задания только руководителя СОГ. Данное правило, обеспечивающее статус руководителя СОГ должно распространятся и на следователей - членов СОГ. При таком подходе, оперативный сотрудник, включенный в состав СОГ, обязан добывать оперативно-розыскным путем информацию, необходимую для расследования уголовного дела.

Оперативный сотрудник включенный в СОГ выполняет указания (в устной, а также письменной форме) руководителя СОГ об осуществлении ОРД; информирует руководителя СОГ о результатах ОРМ; самостоятельно проводить ОРМ в целях получения сведений, имеющих значение для расследования уголовного дела; оперативный работник или руководитель оперативно-розыскной (поисковой) группы, входящий в состав СОГ ведет оперативно-поисковое дело (ОПД) по конкретному уголовному делу по которому создана СОГ; в рамках уголовного дела и ОПД осуществляет взаимодействие с участниками СОГ.

Управление деятельностью оперативного сотрудника или руководителя оперативно-розыскной(поисковой) группы со стороны руководителя СОГ должно строится по принципу обратной связи. Следовательно, оперативный сотрудник или руководитель оперативно- 
розыскной (поисковой) группы обязан информировать руководителя СОГ о результатах выполнения его задач и иных обстоятельствах, которые могут иметь значение для расследуемого уголовного дела, т.е. о сведениях полученных оперативным путем. В свою очередь руководитель СОГ обязан совместно с оперативным работником или руководителем оперативноразыскной (поисковой) группы обязаны осуществить: разработку плана совместных действий, т.е. распределение обязанностей между подчиненными ему следователями и оперативными работниками; поручения на постоянной основе оперативному работнику проведения оперативно-розыскных мероприятий (направление оперативным сотрудникам поручений и указаний о производстве розыскных и поисковых действий; ознакомление с оперативно-разыскной информацией, представляющей интерес по расследуемому уголовному делу; принятие решения об ознакомлении с материалами уголовного дела.

При таком подходе возможна максимально высокая степень организации служебных связей в СОГ, между руководителем СОГ и руководителем оперативно-розыскной (поисковой) группы входящего в состав СОГ.

Например, взаимодействие в сфере расследования экономических преступлений следователю приходится сотрудничать с представителями различных государственных, муниципальных, коммерческих и некоммерческих структур. К примеру, это государственно-территориальные органы Федеральной службы государственной регистрации, кадастра и картографии (Росреестр), ФМС, ФНС.

К негосударственным следует отнести: Центр (бюро) технической, жилищно-коммунальной службы, управляющие домами, банки, нотариальные, риэлтерские службы. Основные формы взаимодействия, это истребование сведений, получение консультаций и участие в качестве специалиста в следственных действиях.

Истребование документов в порядке ч. 4 ст. 21 УПК РФ заключается в письменном запросе в представлении различных документов в которых содержаться сведения: направленные запросы в банки, налоговые органы, 
рассчитаны для обнаружения расчетных счетов; по запросу в органы Росреестра возможно получить краткое описание недвижимого имущества (адреса правообладателей, доля, вид права, наименование и реквизиты правоустанавливающих документах и т.п.; в нотариальных конторах - о сделках совершенных конкретным лицом и документах представленных для совершения сделки; в БТИ - технические и кадастровые паспорта на недвижимость, правоустанавливающие документы от первого до последнего владельца недвижимости, о затратах на ремонт, совершенные в разное время. В жилищно-коммунальные службы (управления, организации, товарищество собственников жилья) можно получить копии лицевого счета на жилье, где отражен механизм отчуждения жилья. Такие сведения можно получить в энергосети, газоснабжении, теплоэнерго и водоснабжении о задолжности или о произведенных оплатах платежей. Эти документа имеют информационный и ориентирующий характер, которые определяют какие следственные действия следует проводить, как неотложные первоочередные или последующие. Например, платежные документы или карточки с образцами подписи и печати имеют криминалистическое значение с точки зрения их исследования на подлинность подписи и печати. Получение консультации: в вопросах определения профессиональных компетенций сотрудников учреждения (налоговая инспекция; регистраторов БТИ или других служб в вопросах формулирования для экспертов), движения документов в жилищном документообороте, имеют важное значение при планировании подготовки выемки или обыска, т.к. они дают возможность на какие документы следует обращать внимание. Знание или наличие информации в вопросах уяснения функциональной структуры организации предприятий и их соподчинённость отдельных организаций, Знание о статусе (права и обязанности) сотрудников, а также анализ должностных инструкций, позволяют выявить и уяснить механизм совершенного преступления в сфере экономической деятельности, осуществить совместное планирование предмета допроса, определить места и предметы обыска или выемки, а также каких специалистов необходимо привлечь к участию в производстве следственных и иных процессуальных действий и OPM. 
При получении консультации у специалиста желательно получить письменную консультацию или самому следователю зафиксировать с согласия специалиста. Руководитель СОГ или следователь вправе при необходимости привлечь специалиста к участию в проведении осмотра места происшествия и документов обнаруженных в ходе осмотра рабочего места, при обыске или выемке, задавать вопросы с разрешения следователя при допросе или очной ставке.

При планировании и организации взаимодействия следственных и оперативно-розыскных подразделений (СОГ) в расследовании многоэпизодных, объемных уголовных дел в сфере экономической деятельности основные усилия должны быть направлены на выявление механизма теневого обращения средств, выведенных из налогообложения; проявлении организованной преступной деятельности и фактов коррупции, связанных с процессом уклонения от уплаты налогов, сокрытия возвращенного НДС или объектов налогооблажения и других преступлений в сфере экономической деятельности.

В связи с изложенным, основными задачами оперативно-поисковой службы экономической безопасности и противодействия коррупции является выявление, раскрытие и принятия в пределах компетенции мер по организации борьбы налоговыми и экономическими преступлениями, обеспечение государственной политики в области экономической безопасности страны. В этих целях установление места нахождения учетнофинансовых, кредитных и иных документов, экономического анализа деятельности предприятия или отдельных участков по вопросам получения доходов и расходов бюджетных федеральных или муниципальных средств, деятельность при изготовлении эмиссии или ценных бумаг или внешнеэкономическая торговля и связи с зарубежными партнёрами. подтверждающих финансово-хозяйственную деятельность; установление лиц, причастных к преступной деятельности, а также степень их участия в совершении преступления.

Изложенное позволяет выделить общие вопросы деятельности СОГ, как информационную работу; совместный поиск информации, на выявление способов подготовки совершения, сокрытия следов преступлений, 
выявление механизма следообразования и противодействия деятельности СОГ путем фальсификации механизма следообразования. Анализ судебноследственной практики и результатов опроса следователей и оперативных работников - участников СОГ можно выделить основные проблемные вопросы взаимодействия, как недостаточно четкое планирование совместной деятельности; разобщенность действий, направленных не на эффективное расследование преступлений, а на гонку за показателями; недостаточно налажен процесс обмена информацией, опыта практикой и методическими рекомендациями по расследованию многоэпизодных экономических и неочевидных тяжких и особо тяжких преступлений, отсутствие координации между следственными и оперативными подразделениями других регионов; отсутствие взаимодействия между подразделениями уголовного розыска (отдел организации раскрытия тяжких и особо тяжких преступлений с отделом организации агентурной оперативной работы и т.п.); низкий уровень исполнительной дисциплины следователя по деловым и психологическим настроем участников СОГ, особенно ее руководителя.

Также выявлены слабые места в организационно-управленческой деятельности участников СОГ, как несоблюдение и неисполнение требований и положений межведомственных нормативных актов; поступление в следственное подразделение недостаточно проработанных и обоснованных материалов документальных проверок, ревизий и т.д., недостаточный уровень профессиональной и психологической подготовки оперативных сотрудников ОВД, следователей Следственного комитета к совместной деятельности.

Как правило, тяжкие особо-тяжкие общеуголовные, а также должностные и экономические преступления подготавливаются и совершаются в условиях глубокой конспирации, а процесс расследования протекает при активном противодействии лиц, не заинтересованных в объективности результатов этого процесса. Такие преступления совершаются организованными преступными группами, преступной организацией, либо сообществом, а значит расследовать их без взаимодействия с оперативно-розыскными подразделениями практически не возможно. Видимо, отдавая предпочтение оперативным службам А.И. 
Бастрыкин высказал мнение о том, что «на новой организованной основе должно выстраиваться сотрудничество с органами осуществляющими оперативно-розыскную деятельность в целях быстрого и эффективного раскрытия преступлений и изобличений виновного» [6].

Использование информационных технологий в организации взаимодействия СОГ автоматизированных информационными системами (ГИАЦ (ИЦ) ГУ МВД РФ по субъекту выдели постоянно действующего представителя в СОГ) как доступ к криминалистическим учетам (антиквариат, валюта, дактилокарт, номерные вещи, пулегильзотека, неопознанных трупов, без вести пропавших, картотека ДНК, Папилон, ИНН и т.д.).

Широкое распространение получает в нашей стране создание единых государственных систем регистрации граждан с использованием цифровых кодов и совокупности идентификационных, в том числе биометрических признаках человека, единой автоматизированной государственной системы регистрации граждан и т.д.

Взаимодействие следователя и органа, осуществляющего ОРД, при выявлении и расследовании мошенничества в сфере потребительского кредитования.

Раскрытие и расследование преступлений, совершаемых в сфере банковской деятельности, в частности, хищения денежных средств заемщиком недостоверных сведений, т.е. мошенничество в сфере кредитования (ст. 159(1) УК РФ). Основная нагрузка по решению оперативно-поисковых задач, комплекс следственных и иных процессуальных действий ложиться на следователя и работников оперативно-розыскных подразделений. Мошенничество в сфере кредитования (ст. 159(1)) УК РФ тесно взаимосвязана со злостным уклонением от кредиторской задолженности, с незаконным получением льготных условий кредитования. Эти преступные деяния достаточно латентны. Вместе с тем, очевидным совершение данного преступления становиться при выявлении злостного уклонения заемщика (физического или юридического лица). При такой ситуации инициатором подачи заявления в органы предварительного следствия и дознания является 
представитель кредитной организации, чаще всего, когда заемщиком является физическое лицо и если это лицо получили потребительский или иной кредит с использованием подложных, или сфальсифицированных документов.

В остальных ситуациях, когда индивидуальные предприниматели или организации своими незаконными действиями получили кредит или их использование носило нецелевой характер, как правило, такая информация поступает от органов осуществляющих оперативно-розыскную деятельность.

Указанные ситуации и обстоятельства предполагают поисковоразведывательный характер совместной деятельности на проверку фактических данных, которыми располагает следствие о местах получения скрываемых документов, средств их изготовления, имущество приобретенное преступным путем, установление круга лиц причастных к преступлению, в частности, из числа работников кредитной организации и какова их роль, установление качества (умения, навыки и т.д.) лиц, участвовавших в преступлении. В зависимости от полученной кредитной суммы, эпизоды преступной деятельности имеют многократность, особенно связанные с многочисленными банковскими операциями. Данное обстоятельство позволяет решить вопрос о создании следственной или следственно-оперативной (поисковой) группы совместно осуществить выявление, раскрытие и расследование преступной деятельности. Следовательно, такая деятельность должна быть согласованной, т.е. совместное планирование процесса совместной работы по отдельным эпизодам, либо следственных действий, осуществляемых совместно; своевременный взаимный обмен информацией при разработке и реализации версий в ходе совместного проведения следственных действий; совместный анализ состояния проведенного следственного действия в целом по делу и в зависимости от следственной ситуации - корректировка плана; совместное обсуждение и принятие решения о производстве следственных действий с соблюдением теории и практики научно-обоснованных организационнотактических приемов. При такой взаимодополняющей деятельности оперативно-розыскной (поисковой) группы было достигнуто объективное 
расследование преступной деятельности, совершенное организованной группой И. в сфере жилищно-коммунального хозяйства.

К сожалению, имеют место в судебно-следственной практике случаи, когда по совершенному преступлению отказывают в возбуждении уголовного дела, ссылаясь на наличие гражданско-правовых отношений, хотя при проверка выясняется иное. Например, в отношении 3. была проведена глубокая проверка и выяснили, что 3. в разных районах края и других областях где ранее он проживал.

По результатам рассмотренных 29 материалов в отношении 3. в порядке надзора было отменено постановление о возбуждении уголовного дела и по всем эпизодам было возбуждено уголовное дело и изобличено в совершении преступлений в составе организованной преступной группы.

Основными приемами возникновения подобных ситуаций является разобщенность территориальных органов, отсутствие взаимной информации о подобных делах по которым отказано в возбуждении уголовного дела.

Анализ многоэпизодных, сложных архивных уголовных дел , а также результаты анализа анкет, по которым опрошены следователи и оперативные работники уголовного розыска и УЭБ и ПК выявил некоторые недостатки во взаимодействии членов СОГ: отсутствие обмена информацией между территориальными органами о материалах отказанных в возбуждении уголовного дела; отсутствие права у следователя знакомиться с оперативными материалами, имеющими отношение к делу и совместного обсуждения этих материалов с оперативными работниками для определения содержания поручаемых с негласными сотрудниками оперативнорозыскных подразделений, а также для принятия согласованного плана проведения следственного действия и ОРМ с использованием конкретного организационно-тактического приема; отсутствие права следователя знакомиться с источником и способом получения оперативно-розыскной информации (в целях конфиденциальности). При планировании многоэпизодных дел следователю - руководителю СОГ следует иметь представление об оперативной работе, специфики и умения осуществлять организационно-методические мероприятия, способствующие искоренению психологической конкуренции или психологической совместимости 
руководителя СОГ и оперативно-розыскной (поисковой) группы участвующего в СОГ, необоснованного ограничения объема предоставленной информации субъектами ОРД со ссылкой на правили конспирации.

В ходе предварительной проверки сообщения возникают типичные следственные ситуации и при их разновидности в условиях предварительной проверки необходимо определить программу действий следователя.

Например, при получении объяснений необходимо определить имеет ли место оговора при допросе. Какие же признаки указывают на это: оно должно быть заявлено заявителем заведомо несоответствующим действительности (быть заведомо ложным). Это определяет насколько оно соответствует событию преступления установленные осмотром места происшествия, осмотром объектов, предметов, документов, о личности по следам обуви, ног, рук, зубов и т.п.; информация должна содержать сведения о преступлении т.е. деянии, которые прямо предусмотрены в норме УК РФ; при квалифицирующих обстоятельствах информация должна относиться к конкретному лицу и конкретному преступлению. При определенных ситуациях, эти признаки достигаются за счет искусственного создания доказательств обвинения конкретного лица в конкретном преступлении. Например, при «провокации» преступной деятельности, как типичного приема позволяющего совершать необдуманные поступки разрабатываемых лиц.

Для того, чтобы распознать необходимо сопоставить деятельность лиц опрошенных и если есть совпадения, что насколько они имеют взаимоотношения, могли ли они быть участниками одного и того же события и проверить насколько их возможно соотнести с реальной обстановкой и обстоятельствами совершенного преступления; необходимо выявить сокрытых очевидных фактов от следователя; не совмещение информации о конкретных деталях произошедшего по признакам и свойствам некоторых объектов - предметов требуется их детализация, которая может исключить противоречия убеждающего в искажении истины. Разногласия между лицами, опрашиваемых по конкретному факту может свидетельствовать о недостаточной согласованности их действий о 
совершенном преступлении или о возможных разногласиях в группе.

При подготовке к одновременному производству комплекса следственных, организационно-управленческих действий имеет важное значение выбор направления расследования, организационно-тактические приемы при их производстве. Предварительное обсуждение и совместно согласованных взаимных действий органа предварительного следствия и дознания зависит от сложившейся следственной ситуации по делу, а также в ситуации в которой оказались участники уголовного судопроизводства на досудебном производстве.

С учетом внесений Федеральным законом России от 4 марта 2013 г. № 23-Ф3 в ст. 144 УПК РФ регламентирующим проведение ряда неотложных следственных и иных процессуальных действий при рассмотрении сообщения о преступлении в целях обнаружения документов, предметов и иных носителей информации о преступлении, криминалистически значимая информация, по результатам оперативно-розыскной деятельности может быть использована в качестве доказательств. Следовательно, в ходе рассмотрения сообщения о преступлении руководитель СОГ или субъект расследования в состоянии самостоятельно определить направление хода расследования, избрать соответствующие тактические операции, приемы осмотра места происшествия, конкретные поручение о проведении ОРМ, получения образцов для сравнительного исследования, назначения судебной экспертизы, истребовать документы, предметы имеющие значение для дела и т.П.

В оперативно-служебных документах (дела оперативного учета, оперативно-поискового дела и т.д.) отражаются материалы с использованием оперативно-технических средств или иной техники с указанием форм и методов полученной информации.

Оперативная информация может быть зафиксирована в справках, актах, рапортах, меморандумах, составленные должностными лицами органа, осуществляющего оперативно-розыскную деятельность с приложением различных объектов со следами преступления, либо материалы полученные с помощью технических средств фиксации (аудиовидео, на магнитных лентах и иных носителях) сообщениях 
конфиденциальных источников.

Результаты оперативно-розыскной деятельности полученных по заданию следователя, дознавателя в ходе проведения предварительной проверки сообщения о преступлении могут быть легитимными как повод и основания возбуждения уголовного дела при условии соблюдения положений ст. 75 и 89 УПК РФ. Данное мнение согласуется с. ч. 1(1) ст. 144 УПК РФ. Например, в ходе рассмотрения заявления К. об исчезновении предпринимателя С. было принято решение о проведении оперативнорозыскных мероприятий и по результатам возбуждено уголовное дело.

В деятельности следственно-оперативной группы свои возможности наиболее в полном объеме могут реализовать только те ведомства и министерства, которые имеют в своем распоряжении такие подразделения, как постоянно действующая дежурная часть, к которой создается СОГ и имеющая в своем распоряжении определенные силы и средства, как ППС и ДПС ГИБДД, экспертно-криминалистические и кинологические службы, особенно, оперативно-розыскные (поисковые) и оперативно-технические службы специализирующиеся на выявлении, раскрытии и расследовании конкретных или однородных групп преступлений или осуществляющих свою деятельность по зонально-линейному принципу раскрытия и расследования преступлений автор, полагает, что такая деятельность руководителя территориального районного, городского и краевого(областного) или республиканского в составе страны, перспективной формой организационно-управленческой деятельности. Следовательно, такой принцип деятельности возможен только в системе МВД России (по раскрытию и расследованию общеуголовных преступлений в сфере экономики), в системе ФСБ (по выявлению, раскрытию и расследованию преступлений против государственной власти и против военной службы и против мира, конституционного строя и безопасности государства и человечества), а также СК России по преступлениям, совершенным против жизни, здоровья, чести и достоинства личности, половой неприкосновенности или половой свободы, конституционных прав и свобод человека и гражданина и прав семьи и несовершеннолетних, а также в сфере экономики, совершенных должностными лицами и т.п. 
В судебно-следственной практике известны три основных вида следственно-оперативных групп, как наиболее мобильные в выявлении, раскрытии и расследовании преступлений. Это: 1) дежурные следственнооперативные группы создаваемые при дежурной части органов внутренних дел для выезда на место происшествия (практике известны, созданные следственные группы подразделений СК РФ при необходимости совместно с СОГ или оперативно-поисковые группы ОВД выезжают на места происшествия); 2) целевые (временные) СОГ, создаваемые для раскрытия и расследования одного или ряда аналогичных преступлений; 3) специализированные (постоянно действующие) СОГ, создаваемые для раскрытия и расследования неочевидных тяжких или особо тяжких, многоэпизодных, с большим объемом выполнения следственных и иных процессуальных действий или преступлений прошлых лет.

В последние годы, стали известны межведомственные и межгосударственные постоянно действующие СОГ. Руководители СОГ, как правило, назначается из числа наиболее опытных следователей, имеющих аналитические и организационно-управленческие умения и навыки деятельности. Этот следователь, руководитель СОГ несет полную личную ответственность за деятельность СОГ, осуществляет взаимодействие всех участников (оперативных работников и следователей, кинологов, экспертов, специалистов, техника-криминалиста), лично проводит следственные и иные процессуальные действия, либо принимает участие в ее производстве, распределяет и руководит работой участников СОГ, координирует их действия, совместно с руководителем оперативной группы определяет направление расследования и наиболее приоритетные оперативнорозыскные (поисковые) мероприятия. Состав и количество участников СОГ зависит от характера, объема, сложности и многочисленности эпизодов преступной деятельности и участников в уголовном судопроизводстве (подозреваемых, потерпевших, свидетелей, очевидцев и предполагаемых количеств следственных действий и ОРМ).

Например, при участии в СОГ специалиста и эксперта, руководитель СОГ должен через специалиста или эксперта (если они не компетентны в даче консультации и проведении экспертизы, например - специалист 
является взрывотехником, а эксперт - судебный медик) организовать подготовку постановления о назначении экспертиз и выборе экспертного учреждения своего ведомства и полученных другим ведомством для оперативного решения производства судебной экспертизы. Таким образом, к участию в СОГ целесообразно вовлекать руководителя ЭКЦ для выполнения разовых поручений по производству судебной экспертизы, а для непосредственного участия на постоянной основе специалиста, техникакриминалиста, и эксперта применительно к расследуемому преступлению. Именно такой подход участия в решении аналитических, организационноуправленческих вопросов функционирования целевых, специализированных и межведомственных вопросов позволит оптимизировать и повысить эффективность деятельности СОГ.

Реализации материалов оперативно-розыскной деятельности предшествует их обнаружение с участием оперативных работников и следователя. При этом необходимо определить количество сил и средств, требующихся для успешного проведения операции, а также составить план реализации в котором отражается: персональный состав следователей и оперативных работников, привлекаемых к реализации; обеспечение работы СОГ силами подразделений наружного наблюдения с подключением в нужный момент группы захвата; расчет необходимых технических средств (средств связи, видеозаписи, автотранспорта); как правило, фактические данные, зафиксированные с применением технических средств обнаруженные, зафиксированные с соблюдением правил предусмотренных ст. 75 УПК РФ.

Это, в первую очередь относиться к записи телефона или иной записи, результаты аудио, видеозаписи, в процессе наблюдения; участия специалиста-криминалиста, с конкретной задачи, стоящей перед участниками СОГ.

Например, в деятельности следственно-оперативной группы при расследовании многоэпизодных, длящихся преступлений, например связанные с незаконным оборотом наркотиков, наркобизнеса и наркомафии возможно выделить следующие формы взаимодействия следователя и оперативного работника, как: согласованное совместное 
планирование деятельности СОГ; обсуждение вопросов процесса расследования, определении направлений расследования; тактики и методов проведения проверки имеющейся информации на первоначальном этапе расследования; планирование следственных действий и оперативнорозыскных мероприятий; взаимное информирование и совместное обсуждение результатов следственных и оперативно-розыскных действий; оперативно-розыскное сопровождение производства отдельных следственных действий.

Формы взаимодействия группы следователей и оперативнорозыскной (поисковой) группы объединенной в СОГ в зависимости от конкретных целей и задач выявления и расследования многоэпизодного преступлений.

Своевременное создание и правильная организация деятельности следственно-оперативной группы, постоянное взаимодействие группой следователей c сотрудниками приданной постоянно действующей оперативно-розыскной группой позволяют успешно раскрывать и расследовать многие неочевидные многоэпизодные тяжкие и особо тяжкие преступления.

Организующей основой первоначального и последующего этапа расследования неочевидных многоэпизодных тяжких и особо тяжких преступлений являются, по мнению диссертанта, комплексные совместные постоянно корректируемые планы проведения следственных действий и оперативно-розыскных мероприятий по конкретному эпизоду многоэпизодного уголовного дела.

Диссертант доказывает, что разработка и апробация организационнотактических и методических и теоретико-прикладных рекомендаций по взаимодействию группы следователей и группы оперативных сотрудников объединенных в единую структуру СОГ является одним из путей повышения результативности борьбы с преступностью.

В результате проведенного анализа научной и специальной литературы, обобщения судебно-следственной и оперативной практики и мнений специалистов - (следователей и оперработников) участников следственно-оперативной группы автор пришел к выводу о том, что в 
деятельности руководителя следственного органа и органа дознания необходимо предусмотреть механизм контроля за исполнением организационных и иных мероприятий, запланированных в системе взаимодействия. Для этого следует использовать аналитический, организационно-методический штаб по управлению взаимодействием членов СОГ.

Автор также полагает, что в соответствии с ч. 1 ст. 144 УПК РФ на основании письменного поручения следователя, орган дознания в о проведении оперативно-розыскных мероприятий, наряду с рассмотрением сообщения о преступлении, вправе проводить доследственную (предварительную) оперативную проверку в соответствии с задачами оперативно-розыскной деятельности, послужит основанием взаимодействием на стадии возбуждения уголовного дела. Автор констатирует о возможном одновременном существовании процессуальной и непроцессуальной формы взаимодействия между сотрудниками органа предварительного следствия и дознания. Автор убежден в том, что результаты ОРД, полученные в ходе ОРМ, должны использоваться на всех стадиях уголовного судопроизводства (при рассмотрении сообщения о преступлении, на первоначальном, последующем и заключительном этапе расследования и судебного разбирательства, а также при исполнении обвинительного приговора). На протяжении всей деятельности СОГ необходимо осуществлять взаимодействие между сотрудниками органов предварительного следствия и дознания, а также должностных лиц осуществляющих ОРД. Представляется, что под формами взаимодействия следует понимать комплекс совместных согласованных уголовно-процессуальных и организационно-управленческих действий следователя, руководителя СОГ и органа дознания, на основе оперативной или оперативно-тактической готовностью построенных в сочетании методов оперативно-розыскной деятельности и процессуальных действий с соблюдением принципов уголовно-процессуального законодательства и Ф3 «Об ОРД» для непосредственного выполнения назначения уголовно-процессуального законодательства и решения задач ОРД. 
В специальной литературе под оперативной или оперативнотактической готовностью органов внутренних дел обычно имеют в виду состояние его служб и подразделений, при котором обеспечивается быстрый и организованный ввод в действие всего комплекса взаимодействующих между собой сил и средств в целях осуществления активных наступательных действий по выявлению, раскрытию, розыску подозреваемых, а также задержанию преступников.

Оперативная готовность управления расследованием преступления через деятельность следственно-оперативной группы по раскрытию неочевидных, многоэпизодных тяжких и особо тяжких преступлений, например, убийств совершенных по найму, похищения человека должна основываться на системе оперативной осведомлённости о фактах и лицах, прямо или косвенно причастных $\kappa$ подготовке или совершению преступлений. Такая система может создаваться и функционировать в рамках специализированного информационно-аналитического подразделения (штаб) входящего в структуру специализированной, постоянно действующей следственно-оперативной группы для выявления, раскрытия и расследования неочевидных, замаскированных преступлений и запутанных уголовных дел прошлых лет, имеющих региональный и межрегиональный характер. Информационно-аналитическое подразделение, как правило, занимается сбором и накоплением, хранением и анализом, оценки и выдачи оперативно-розыскной и криминалистически значимой информации заинтересованным пользователем для проведения следственных действий, а также оперативно-розыскных мероприятий, т.е. управлением расследования преступлений.

При взаимодействии участников СОГ, особенно, руководителя следователей и руководителя оперативно-розыскного подразделения в процессе расследования многоэпизодного, сложного, с большим объемом работы, неочевидных тяжких и особо тяжких преступлений и преступлений, совершенных преступными группами. В целях повышения эффективности взаимодействия необходимо: при создании таких групп учитывать психологические особенности ее участников; обеспечить знакомство руководителя СОГ и следователя с имеющимися оперативными 
материалами и на их основе совместную разработку плана по их реализации; систематически проводить анализ и оценку реализованных процессуальных и розыскных материалов, с целью выявления типичных ошибок и просчетов, а также меры по их устранению; производить совместные обсуждения по разработке плана комплексных операций, сочетающих в себе оперативнорозыскные мероприятия, следственных и иных процессуальных действий. По результатам их проведения при необходимости корректируются, либо разрабатываются частные планы мероприятия.

Одной из особенностей работы по делам о тяжких, особо тяжких преступлений, совершенных преступными группами, является ограниченность возможностей получения процессуальным путем криминалистически значимой и доказательственной информации. Поэтому, по делам рассматриваемой категории, следует перенести акцент на проведение оперативно-розыскных мероприятий с использованием информационных, тактических и прогностических основ ОРД.

Вместе с тем специфика совершенствования организационноинформационной, тактической и прогностической формы взаимодействия требует, высокий уровень организации и обеспечения организованной взаимной информацией руководителя группы следователя и руководителя оперативно-розыскной группы входящего в состав СОГ. Наиболее эффективной формой взаимодействия участников СОГ является непосредственное ознакомление следователя с материалами оперативнорозыскного документирования, полученного путем оперативного поиска, результатами разработок фигурантов с использованием специального технического обеспечения.

В зависимости от конструкции состава и признаков конкретного преступления формируются особенности взаимодействия участников СОГ с учетом сложившейся следственной ситуации.

Например, при раскрытии и расследовании бандитизма или преступлений, совершенных бандформированиями необходимо выявить определить следственные ситуации, складывающихся в ходе рассмотрения сообщения о преступлении и первоначального и последующего этапа расследования. В ходе рассмотрения сообщения о совершенном 
преступлении, как бандитизм зависит от сложившейся следственной ситуации, таковыми могут быть: отсутствие достаточной информации об устойчивости, вооруженность бандгрупп, о руководителе микрогрупп и в целом о руководстве бандой, о лицах не вступивших в банду, но участвующих в деятельности банды путем финансовой поддержки. В целях проверки следственных ситуаций необходимо через местных конфиденциальных источников получить необходимую криминалистически значимую (ориентирующую и доказательственную) информацию. На первоначальном и последующем этапе расследования бандитизма или преступлений совершаемых ОПГ могут быть четыре следственные типичные ситуации: преступление совершено в условиях неочевидности; потерпевший убит или находится в тяжелом состоянии; преступники скрылись; бандиты с места происшествия скрылись, имеются очевидцы и свидетели; преступники задержаны на месте происшествия, имеются очевидцы и свидетели; преступники захватили автотранспортное или авиационное средство или же населенный пункт и удерживают заложников.

В ходе проведения следственных действий и оперативно-розыскных мероприятий на первоначальном этапе расследования может быть использован следующий алгоритм действий: осмотр места происшествия; задержание подозреваемого и его допрос; проверка и уточнение показаний на месте происшествия, документов и предметов со следами преступления, обыск или выемка с целью изъятия вещественных доказательств.

На последующем этапе расследования могут быть проведены: одновременные обыски у подозреваемых и других лиц; выемка; осмотр оружия и орудий совершения. Раскрытие и расследование преступлений по делам о преступлениях, совершенных бандой, во многом зависит от правильного использования процессуальных и не процессуальных форм взаимодействия следователя с оперативно - розыскными и иными работниками органами дознания, особенно на первоначальном этапе расследования.

В ходе расследования преступлений совершенных бандформированиями требует от различных служб и подразделений проведения соответствующих организационно-аналитической, 
управленческой деятельности, например: подразделения по борьбе с организованной преступностью представляют оперативно-справочные материалы по разработке деятельности банд; совместно с отдела организации раскрытия тяжких и особо тяжких преступлений проводят оперативно-розыскные (поисковые) мероприятия; оперативный дежурный дежурной части и ответственный от руководства ОВД при получении информации о совершенном преступлении обеспечивают охрану мест происшествий; осуществляют задержание преступников; к этой деятельности привлекают к поисковой работе полицейских патрульнопостовой службы и ГИБДД; информируют об обстоятельствах совершения преступления о приметах подозреваемых лиц, похищенном имуществе; своевременно передают ориентировки; сотрудники экспертнокриминалистического подразделения, участвующего в СОГ, формируют все документа и предметы со следами преступления и микрообъкты, а также другие сведения и проверяют по соответствующим учетам, коллекциям и картотекам, выявляют и фиксируют следы и проверяют по имеющимся учетам, проводят предварительное исследование вещественных доказательств; оперуполномоченные оперативно-технического подразделения (Бюро специальных технических мероприятий) по поручению руководителя СОГ проводят оперативно-розыскные (поисковые) мероприятия и операции по документированию преступной деятельности. Полученные результаты подлежат осмотру, проверке, оценке и судебной экспертизе с последующей оценкой в совокупности с другими доказательствами по делу.

Важным участником при проведении следственных действий по многоэпизодным, сложным, с большим объемом выполнения следственных и иных процессуальных действий является специалист-криминалист, техник-криминалист, следователь-криминалист, осуществляющий поиск, обнаружение, фиксацию, изъятие, осмотр, проверка, оценка, транспортировка вещественных доказательств, особенно, при производстве осмотра места происшествия, обыска, осмотра документов и предметов. В процессе деятельности специалиста, они также могут осуществлять справочно-консультационную деятельность, например, по описанию свойств 
и признаков объекта и их поиск по криминалистическим учетам, коллекциям и т.д.

Участие специалиста (техника-криминалиста) в следственной и оперативно-розыскной (поисковой) деятельности, также предполагает оказание следователю и оперативному сотруднику любую помощь, которая не выходит за рамки его знаний для совместного или самостоятельного исследования предоставленных документов, имеющих отношение к делу полученных с использованием процессуальных или непроцессуальных методов и средств поиска криминалистически значимой информации. Такая деятельность позволяет проверять и перепроверять достоверность полученной информации оперативно-розыскными методами и средствами, в целях предотвращения ошибок в принятии процессуальных решений. Сочетание гласных и негласных методов получения оперативной информации с участием специалиста (техник) - криминалиста обеспечивает необходимую конспирацию и зашифровку конфиденциальных источников информации, гарантируя таким образом, конституционное право граждан на личную тайну. Специалист-криминалист обязан применять все имеющиеся специальные знания, для всестороннего, полного и объективного исследования обстоятельств дела, а также принять меры к установлению причин и условий произошедшего события. Он вправе предлагать версии следователю и оперативному работнику на основе проведенного исследования, подлежащих проверке оперативным путем.

T.А. Аверьянова обращает внимание некоторым проблемам консультационной деятельности специалиста-криминалиста в уголовном судопроизводстве, имея ввиду об отсутствии нормы в уголовнопроцессуальном законодательстве[7]. В уголовно-процессуальном законе имеется норма, предусмотренная ст. 58 УПК РФ введения Федеральным Законом от 4 июля 2003 г. № 92-ФЗ где изложен, процессуальный статус и определение понятие специалиста.

Конечно в содержании положений норм ч. 1 и 3 ст. 58 УПК РФ непосредственно не отмечена деятельность специалиста, как справочноконсультационная деятельность, но и по отдельным фрагментам как «для постановки вопросов эксперту» возможно предположить, как предложение 
специалиста для «решения», «выполнения» и «обсуждения» чего-нибудь[8].

При таком решении возможно предположить, что консультанты совместно с субъектом назначения обсуждают вопросы подлежащие отражению в постановлении о назначении экспертизы. Далее, в другом словосочетании, как «а также для разъяснения сторонами и суду вопросов, входящих в его профессиональную компетенцию» указанного в последнем абзаце ч.1 ст. 58 УПК РФ по нашему мнению означает, что специалист разъясняет следователям, дознавателям, суду, прокурору, защитнику. Он одновременно осуществляет справочную консультационную деятельность, т.к. слово «разъяснить» в современном русском языке означает «объяснить, сделать ясным, понятным»[9]. Автор этих строк не претендует на окончательное понимание словосочетаний, указанных в ч. 1 ст. 58 УПК РФ (специалист) как часть для справочно-консультационной деятельности специалиста.

К сожалению, в уголовно-процессуальном законодательстве относительно специалиста не предусмотрены условия и порядок его деятельности, как основные правила поведения специалиста. В ст. 5 УПК РФ (основные понятия используемые в настоящем Кодексе) и в других нормах этого закона не предусмотрено понятие и процессуальный статус «специалиста-криминалиста», что затрудняет использование информации (сведений) полученной в виде консультации специалиста-криминалиста как процессуальная форма деятельности.

Используя общие принципы, предложенные В.Н. Маховым, автор предпринял попытку адаптировать их в качестве криминалистических принципов. Например, принцип законности для справочноконсультационной деятельности специалиста-криминалиста означает, деятельность только в случаях и порядке, установленном в законе. Согласно ч. 1 ст. 144 УПК РФ в предварительной проверке сообщения о преступлении, субъект, производящий данную деятельность вправе во время производства документальных проверок, ревизий, исследований документов, предметов, трупов, привлекать к участию в этих действиях специалистов, а ч. 5 ст. 164 УПК РФ предписывает, что в следственных действиях следователь вправе допустить и специалиста, и, согласно ч. 6 ст. 
164 УПК РФ при производстве следственных действий могут применяться технические средства и способы обнаружения, фиксации и изъятия следов преступления и вещественных доказательств». Естественно к такой деятельности может быть допущен только специалист-криминалист (следователь-криминалист) [10]. Следовательно, специалист-криминалист в уголовном судопроизводстве принимает участие на законных основаниях. В этой ситуации, специалист-криминалист осуществляет справочноконсультационную деятельность. Это и подтверждается опосредовано положением ст. 168 УПК РФ.

Объективность специалиста в осуществлении справочноконсультационной деятельности означает отсутствие его личной заинтересованности в исходе дела (см.: ст. 61, 69, 70 и 71 УПК РФ), а также представляемые специалистом справочные сведения и консультации должны быть по своему содержанию исчерпывающими с точки зрения количественной и качественной характеристики в соответствии с существующей справочной карточки, коллекции, различных видов криминалистических учетов (антиквариат, номерные вещи, дактилоскопия и т.п.) и научно-обоснованные криминалистические рекомендации по их описанию и т.д.

В уголовно-процессуальном законодательстве непосредственно не предусмотрено понятие объективность, всесторонность и полнота исследования обстоятельств дела, однако опосредованно об этом изложено ст. 6 УПК РФ (назначение уголовного судопроизводства) и в ст. 7 УПК РФ. В связи с этим справедливо возникает, вопрос о возможном существовании криминалистических принципов в справочно-консультационной деятельности специалиста-криминалиста. К таковым можно отнести соответствие уголовно-процессуальных принципов общетеоретических и методических основ, криминалистической науки. Следовательно результаты деятельности специалиста-криминалиста должны быть основаны на соблюдении криминалистических научно-обоснованных научных и практических рекомендаций.

Справочно-консультационная деятельность специалистакриминалиста необходимо трактовать с позиции ситуационного подхода в 
выборе и применений научно-технических и тактических приемов (методов) для обнаружения, фиксации, установки, транспортировке и хранения вещественных доказательств, их исследования, проверки, оценки и использования в качестве криминалистически значимой информации (ориентирующей и доказательственной) по делу в ходе следственных и иных процессуальных действий, на основе методологии (приемы, способы, методы, операции, комбинации и средства) и оценки ситуации даст соответствующую консультацию по вопросу следователя.

Использованию всех криминалистических принципов с учетом сложившейся ситуации должны соответствовать справочноконсультационная деятельность (научных и научно-практических) уровню профессиональной подготовки на основу ситуационного подхода к выбору и применения научно-технических и тактических приемов (методов) для обнаружения, фиксации, установки, транспортировки и хранения вещественных доказательств, их использования, проверки, оценки и использования в качестве криминалистически значимой информации (ориентирующей и доказательственной) по делу в ходе следственных и иных процессуальных действий, на основе методологии (приемы, способы, методы, операции, комбинации и средства) и оценки ситуации дат соответствующую консультацию по вопросу следователя.

Использование всех криминалистических принципов с учетом сложившейся ситуации должны соответствовать справочноконсультационная деятельность (научно и научно-практические) уровни профессиональной подготовки на основе ситуационного подхода в конкретном случае в сочетании с личной компетентностью (обладание достаточными данными о предмете, осведомленность в каком-нибудь круге вопросов, какой-нибудь отрасли знания, знания и опыт той или иной области, область знания или практика, в которой данное (компетентное) лицо обладает обширными, точными знаниями и опытом практической деятельности, инициативностью, реальностью, индивидуальностью и конкретностью.

Рассмотрение криминалистических принципов представляет собой определенные теоретические основы, в соответствии с которыми можно 
раздавать конкретные научно-практические рекомендации относительно справочно-консультационной деятельности специалиста, в частности, специалиста-криминалиста.

На основании изложенного автор определяет общее определение понятия взаимодействия в уголовном судопроизводстве, т.е. взаимодействие в уголовном судопроизводстве - это уголовное преследование, осуществляемое надлежащими субъектами правомочных осуществлять уголовное судопроизводство и участвующих лиц на основе уголовнопроцессуального закона, Федеральных законов и нормативно-правовых актов, регулирующих их деятельность в целях реализации единого согласованного плана совместных действий по выявлению, раскрытию и расследованию неочевидных преступлений.

Взаимодействие в следственно-оперативной группе, автор определяет, как взаимодействие двух систем или подразделений правоохранительных органов и других привлекаемых к участию лиц, осуществляющих уголовное преследование, т.е. следственная группа и оперативно-розыскная (поисковая) группа, основанная совместным постановлением руководителя следственного органа и органа дознания (ОВД) и осуществляющая свою процессуальную и непроцессуальную деятельность на основе уголовнопроцессуального закона, Федеральных законов и нормативно-правовых актов, регулирующих их деятельность в целях реализации согласованного совместного плана действий по выявлению, раскрытию, расследованию неочевидных, многоэпизодных тяжких и особо тяжких преступлений.

\section{Литература}

1. Гордин А.В. Взаимодействие оперативно-розыскных подразделений и следователя органов внутренних дел при раскрытии и расследовании преступлений: автореф. дис. ...канд. юрид. наук/ А.В. Гордин. -СПБ, 2005. - С. 26.

2. Усынин В.М. Процессуальные формы взаимодействия органов предварительного следствия и органов, осуществляющих оперативно-розыскную деятельность по уголовным делам на досудебных стадиях уголовного процесса: автореф. дис. ...канд. юрид. наук / В.М. Усынин. - Ижевск, 2005. С. 18.

3. Докучаев О.О., ст. следователь военного следственного отдела - в/ч 68796 г. Мурманска. Вестник криминалистики. М., 2008, выпуск № 3(27).

4. Эксархопуло А.А. Взаимодействие следователя с оперативно-розыскными и иными государственными органами при раскрытии и расследовании преступлений // Криминалистика: Учеб./ Под ред. Т.А. Саровой, А.А. Эскархопуло. СПб, 2001. с. 447 - 
448; Беляев И.И. О средствах повышения эффективности взаимодействия следственного аппарата с ОВД при расследовании убийств // Следственная практика, НИИ проблем укрепления законности и правопорядка при Генпрокуратуре РФ. М., 2005. Выпуск 166. С. 42.

5. Кузнецов М.С, Взаимодействие следователей военной прокуратуры с органами дознания при расследовании преступлений: Дис. ...канд. юрид. наук. М., 2002. C. 146-150.

6. Об основных итогах работы следователя Следственного Комитета за 2007 год: Выступление Председателя СК РФ А.И. Бастрыкин / Вестник Следственного Комитета при Прокуратуре РФ. М., 2008. № 1.С. 14.

7. Аверьянова Т.В. Судебная экспертиза. Курс общей теории. М., 2008. С.178179.

8. Ожегов С.И. Словарь русского языка / Под ред. Н.Ю. Шведовой, - М.; изд-во «Русский язык», 1986. С. 492661.

9. Ожегов С.И. Указ. Соч. с. 569.

10. Статья 168 УПК РФ (Участие специалиста). См.: УПК РФ по состоянию на 10 октября 2015 г./М.: Проспект, КноРус, 2015. - 97 с.10

\section{References}

1. Gordin A.V. Vzaimodejstvie operativno-rozysknyh podrazdelenij i sledovatelja organov vnutrennih del pri raskrytii i rassledovanii prestuplenij: avtoref. dis. ...kand. jurid. nauk/ A.V. Gordin. -SPB, 2005. - S. 26.

2. Usynin V.M. Processual'nye formy vzaimodejstvija organov predvaritel'nogo sledstvija i organov, osushhestvljajushhih operativno-rozysknuju dejatel'nost po ugolovnym delam na dosudebnyh stadijah ugolovnogo processa: avtoref. dis. ...kand. jurid. nauk / V.M. Usynin. - Izhevsk, 2005. S. 18.

3. Dokuchaev O.O., st. sledovatel voennogo sledstvennogo otdela - v/ch 68796 g. Murmanska. Vestnik kriminalistiki. M., 2008, vypusk № 3(27).

4. Eksarhopulo A.A. Vzaimodejstvie sledovatelja s operativno-rozysknymi i inymi gosudarstvennymi organami pri raskrytii i rassledovanii prestuplenij // Kriminalistika: Ucheb./ Pod red. T.A. Sarovoj, A.A. Jeskarhopulo. SPb, 2001. s. 447 - 448; Beljaev I.I. O sredstvah povyshenija effektivnosti vzaimodejstvija sledstvennogo apparata s OVD pri rassledovanii ubijstv // Sledstvennaja praktika, NII problem ukreplenija zakonnosti i pravoporjadka pri Genprokurature RF. M., 2005. Vypusk 166. S. 42.

5. Kuznecov M.S, Vzaimodejstvie sledovatelej voennoj prokuratury s organami doznanija pri rassledovanii prestuplenij: Dis. ...kand. jurid. nauk. M., 2002. S. 146-150.

6. Ob osnovnyh itogah raboty sledovatelja Sledstvennogo Komiteta za 2007 god: Vystuplenie Predsedatelja SK RF A.I. Bastrykin / Vestnik Sledstvennogo Komiteta pri Prokurature RF. M., 2008. № 1.S. 14.

7. Averjanova T.V. Sudebnaja jekspertiza. Kurs obshhej teorii. M., 2008. S.178-179.

8. Ozhegov S.I. Slovar russkogo jazyka / Pod red. N.Ju. Shvedovoj, - M.; izd-vo «Russkij jazyk», 1986. S. 492661.

9. Ozhegov S.I. Ukaz. Soch. s. 569.

10. Statya 168 UPK RF (Uchastie specialista). Sm.: UPK RF po sostojaniju na 10 oktjabrja 2015 g./M.: Prospekt, KnoRus, 2015. - 97 s.10 